\title{
Preface
}

Musicians today are caught up in a movement to study and explore the use of old musical instruments. The flute generating the most interest is the eighteenth-century one-keyed flute. A growing number of flutists are purchasing modern replicas and learning to play them.

Not long ago the one-keyed flute was considered an inadequate predecessor of the modern flute. In 1966 René LeRoy (p. 14) described the eighteenth-century flute as a "very imperfect instrument." The writer of a doctoral essay at Eastman said that the one-keyed flute's inferior pitch quality and inferior tone quality were natural and unavoidable flaws in the instrument (Hartman, 1961, p. 16). Generally, flutists had no desire to learn to play this simple one-keyed instrument when a "perfected" flute was available to them.

However, attitudes have changed during the past thirty to forty years. Concerts and professional recordings featuring historic flutes are no longer rarities. Workshops specializing in the manufacture of historical flutes and music publishers specializing in scholarly editions of early music support these performance activities.

Flutists who experiment with the one-keyed flute find that it is indeed an instrument of merit. Innate in the simplicity of its structure are unique expressive qualities not inherent in the modern Boehm-system flute.

This method book is written for players of the Boehm-system flute who are already familiar with tone production and modern flute technique: it is designed to help with the flutist's initial approach to the one-keyed flute. The Method can serve as a self-guiding tutor or as a text when the flutist is working with a teacher. It is not intended to be a musicological treatise, but a practical and useful guide which cites historical sources. These historical sources offer a broad diversity of opinions which challenge us to explore the ideas of eighteenth-century writers and incorporate them into our present-day experience.

The Method addresses such topics as choosing a flute and assembling the instrument, to more advanced concepts such as tone color and eighteenthcentury articulation patterns. Discussions of tone, intonation, and tonality will help guide the student in exploring the expressive nature of the instrument. Fingering charts, exercises, and eighteenth-century tunes will help the student get started. To encourage the reader to explore primary historical sources, the "Top 13" eighteenth-century flute tutors are reviewed with reference given to present-day facsimile editions and translations. Those new to the one-keyed flute will be helped by the annotated repertoire list of easy solos, duets, and studies. The annotated bibliography references both historical and modern sources. 
Many texts on eighteenth-century technique and style are currently available, both as primary sources (from eighteenth-century authors) and secondary sources (in this case, twentieth-century writings regarding eighteenth-century performance style). The scope of this book does not allow for any more than a mention of some of the more important techniques and performance styles. Textbooks and articles by leading scholars are referenced throughout the text and included in the annotated bibliography to encourage the reader to become familiar with these important sources.

Your reasons for exploring the one-keyed flute may range from mere curiosity to a desire to master the instrument for the purposes of public performance. Even if you wish only to experiment with the one-keyed flute, doing so will give you important insights that you will find useful for modern, Boehm-system flute performances.

\section{EDITORIAL CONVENTIONS}

To avoid extensive footnotes, publication date (and page numbers where there are quotations) of the sources referenced are given in parentheses within the text following the author's name. Complete bibliographic entries are found in the annotated bibliography.

In quoting foreign language sources, references are made to available English translations. For example, page numbers for quotes of the Quantz tutor refer to the Reilly translation listed in the bibliography.

The exercises and tunes in Chapter Four come from eighteenth- and nineteenth-century flute tutors and collections. The exercises or tunes credit the composer (where known), the author (in the case of a treatise which has not identified the composer of its tunes), or the title of a collection. Edited slurs are shown by means of a dashed slur. Breath mark indications are mine, with the exception of the little duet in e minor by Blavet, who frequently indicated his own breaths. Trills very often begin from the note above the principal note-there are exceptions. The performance suggestions for the tunes in this Method are based on the instruction given in the tutor from which the tune was taken.

I have used the letters $d^{\prime}-b^{\prime}$ for notes of the first octave, $c^{\prime \prime}-b^{\prime \prime}$ for the second octave, and c"'-a"' for the third octave.

I have used the capital letter when describing a particular major key, such as $\mathrm{G}$ major, and a lower case letter when describing a minor key, such as e minor.

To simplify the layout, fingerings in Chapter Four are given using a simple number system instead of the graphics found on the charts. For example, $g^{\prime}$ is designated $123 / \ldots$ 